\title{
De la seguridad a la prevención: gripe A (H1N1), un nuevo desafío para los intensivistas
}

\author{
Alejandro Rodríguez a,b,*, Thiago Lisboa a, Emili Díaz a, J ordi Rello a y Cristóbal León ${ }^{c, d}$
}

\author{
a Servicio de Medicina Intensiva, Hospital Universitari J oan XXIII, Universidad Rovira i Virgili, IISPV, CIBER Enfermedades \\ Respiratorias (CibeRes), Tarragona, España \\ ${ }^{b}$ Vice-Coordinador Grupo de Trabajo de Enfermedades Infecciosas (GTEI) de la Sociedad Española de Medicina Intensiva, \\ Crítica y Unidades Coronarias (SEMICYUC), España \\ 'Servicio de Cuidados Críticos y Urgencias, Hospital Universitario de Valme, Sevilla, España \\ dPresidente de la Sociedad Española de Medicina Intensiva, Crítica y Unidades Coronarias (SEMICYUC), España
}

El 11 de abril de 1912, y cuando el reloj marcaba exactamente las 13.30 horas, el Titanic partió en su viaje inaugural desde el puerto de Queenstown con 902 tripulantes y más de 1.400 pasajeros. Considerado por los ingenieros de la época como un barco incapaz de hundirse, levó anclas.

Desde el 24 de marzo al 24 de abril de 2009, 18 casos de neumonía por el nuevo virus de la gripe A (H1N1-SOIV) han sido identificados en un grupo de 98 pacientes hospitalizados por insuficiencia respiratoria grave en Ciudad de México ${ }^{1}$.

El mayor trasatlántico del mundo, el Titanic, tras sólo 3 días de navegación, sucumbió ante un iceberg cuando el oficial al mando ordenó una brusca maniobra evasiva que produjo una enorme grieta de 80 metros en estribor. Tras algo más de 2 horas el Titanic se hundió en las frías aguas del Atlántico Norte originando la muerte de más de 1.500 personas.

Poco después de confirmarse la transmisión interhumana en al menos 3 países, la Organización Mundial de la Salud elevó el nivel de pandemia al máximo² y a partir de aquí el número de casos se fue incrementando exponencialmente hasta llegar a 94.512 pacientes con confirmación microbiológica y 429 muertes en el boletín de fecha 6 de julio $2009^{3}$.

Tal vez, y como el capitán del Titanic, los médicos hemos considerado que esta nueva gripe $\mathrm{A}(\mathrm{H} 1 \mathrm{~N} 1)$ era una entidad muy contagiosa pero segura, ya que de todos los infectados, menos del $1 \%$ han muerto ${ }^{3}$ y muchos de ellos con aparentes

\footnotetext{
*Autor para correspondencia

Correo electrónico: ahr1161@yahoo.es (A. Rodríguez).
}

comorbilidades que los convertían en huéspedes susceptibles. Sin embargo, nuestro iceberg estaba muy cerca y pronto caímos en la cuenta de que aquella seguridad con la que partimos se ha visto rápidamente reemplazada por una sensación de cierta inseguridad y desconocimiento de esta nueva entidad. La alta contagiosidad y el hecho de que la mayoría de pacientes presenten poca limitación de su actividad habitual suponen un mayor riesgo, ya que el denominador para la estimación de la incidencia resulta muy elevado.

Desde el nuevo continente, las noticias sobre el impacto de la gripe A (H1N1) no podían ser peores. De Ios 12.547 pacientes infectados en Latinoamérica, $78(0,6 \%)$ han fallecido, la mayoría de ellos en Argentina y $\mathrm{Chile}^{4}$, sin que se cuente con datos oficiales acerca de qué porcentaje de pacientes hospitalizados finalmente fallece. Por otro lado, países como Estados Unidos y Canadá, con una gran infraestructura en salud y experiencia en el manejo de epidemias graves como el SARS 5 , comunican una mortalidad sensiblemente superior (cercana al 4,5\%) de los pacientes que deben ser hospitalizados ${ }^{6}$. Sólo 6 semanas después del primer caso, Winnipeg, en Canadá, cuenta con 65 casos de neumonía H1N1 con confirmación microbiológica, cuando la capacidad de las UCl de la ciudad es de 75 camas.

En Europa, con cerca de 10.000 casos registrados y especialmente en España, mientras disfrutamos de nuestro merecido verano y vemos a la pandemia como una entidad ajena y lejana, nos vamos informando día a día de que el número de infectados se sitúa próximo ya a $900^{7}$, y la primera muerte por H1N1 se produjo hace unos pocos días.

Nuestra experiencia con los primeros casos graves confirmados microbiológicamente es más que preocupante. Los 
factores de riesgo habituales no se cumplen y afecta a pacientes de 5-52 años con sobrepeso (mortalidad 12 veces elevada en la franja 20-24 años), así como a embarazadas de más de 20 semanas de gestación sin comorbilidades. El cuadro se inicia de forma aguda con fiebre intensa, superior a $39{ }^{\circ} \mathrm{C}$, que no cede con antitérmicos ni con los antimicrobianos habituales, con presencia de tos irritativa sin expectoración. A esto se asocia elevación notable de la LDH con disociación clínico-radiológica importante y un incremento de la CPK con cierto grado de disfunción renal, signos de que deberán ser considerados de gravedad. La tomografía de tórax suele presentar extensas áreas de infiltrado alveolar e intersticial, con áreas de colapso pulmonar. La presencia de diarrea (frecuente en niños) es un signo de mal pronóstico en adultos. La utilidad de scores de gravedad como el PSI ${ }^{8}$ o el CURB- $65^{9}$ parece «poco rentable» en casos de gripe A (N1H1) por la subestimación de la gravedad en este tipo particular de población, siendo de utilidad la determinación precoz de la oximetría de pulso en el momento de valorar la gravedad en el departamento de urgencias ${ }^{10}$. Dado que se han comunicado falsos negativos para PCR en muestras de secreción nasal que son positivos tras obtener secreción traqueal, ante un cuadro clínico compatible se deberá iniciar tratamiento antiviral con oseltamivir y obtener secreciones respiratorias si está intubado.

La progresión de la hipoxemia es muy rápida. En 72 horas el cuadro de insuficiencia respiratoria se convierte en severo, con necesidad de altas concentraciones de oxígeno inspirado y rápidamente ventilación mecánica. Una vez ventilado, la $\mathrm{PaO}_{2} / \mathrm{FiO}_{2}$ oscila en $100-200$ y es necesaria la utilización de PEEP elevadas ( $>20$ ), con lo que se obtienen mejoras en los valores de compliancia estática. La hipoxemia es muy sensible a la disminución de la PEEP y mejora con el balance hídrico equilibrado. Curiosamente, la ecocardiografía muestra signos de disfunción miocárdica muy precozmente, con reducción en la fracción de eyección < $50 \%$ Además, inicialmente, y a pesar del severo componente respiratorio, no se aprecia lactacidemia ni acidosis metabólica, que se manifiesta con el paso de los días posiblemente en relación con la instauración de un fracaso renal agudo que, habitualmente, requiere técnicas de reeemplazo renal. No está claro si la lesión pulmonar es de origen immunológico o se trata de neumonitis viral, pero se han descrito recaídas si el tratamiento se suspende a los 5 días. El tratamiento precoz con antivirales, con pautas que contemplen altas dosis y más duración que las habituales, para los pacientes críticos (oseltamivir, $15 \mathrm{mg} / \mathrm{kg} /$ día durante 10 días) y el tratamiento ATB en combinación conjuntamente con alguna pauta corta de esteroides son las estrategias más utilizadas en los protocolos de acción internacionales. El tiempo medio de ventilación mecánica es de 5 semanas, periodo en el que deberán mantenerse todas las medidas de aislamiento respiratorio estricto, hasta que la PCR/cultivos de secreción traqueal sea negativa para el virus.

Si el capitán del Titanic hubiera sido menos confiado y más atento, habría divisado el témpano de hielo a distancia y posiblemente la historia sería otra. Nuestra función como intensivistas, y desde la SEMICYUC, es alertar del peligro potencial de esta pandemia a las diferentes instituciones de salud, ahora que hay tiempo para preparar planes de acción. No es cierto que asistiremos a un porcentaje mínimo de pacientes infectados. Si se repiten los números comuni-

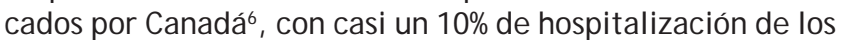
pacientes infectados, y se ha calculado que cerca de un $10 \%$ de la población española presentará la gripe A (H1N1) en el próximo invierno, más de 400.000 españoles estarán infectados y 4.000 de ellos deberán ser hospitalizados con riesgo de presentar una forma grave de neumonía viral con una elevada morbimortalidad; se sumarán a los cientos de hospitalizados habituales en las $\mathrm{UCl}$ de este país. Seis semanas después se espera una segunda oleada de insuficiencia respiratoria por síndrome de Guillain-Barré.

La implementación de un plan de acción multidisciplinario coordinado desde la $\mathrm{UCI}$, que contemple no sólo el reconocimiento y tratamiento precoz de esta entidad, sino también la dotación de la infraestructura necesaria en el hospital, y sobre todo a los servicios de medicina intensiva, a fin de poder brindar la mejor asistencia a los casos más graves, nos permitirá asegurar con éxito un desenlace favorable para este nuevo desafío al que todos los españoles estamos y estaremos expuestos. Considerando que el $80 \%$ de los pacientes hospitalizados en Canadá se encuentran en una $\mathrm{UCl}$, no cabe duda de que se trata de un proceso en el que los intensivistas españoles ofrecerán todo su conocimiento y dilatada experiencia, al igual que en otras situaciones, en el manejo de las complicaciones graves respiratorias y asociadas que esta pandemia puede condicionar en nuestro país.

\section{Bibliografía}

1. Pérez-Padilla R, De la Rosa-Zamboni D, Ponce de León $S$, Hernández $M$, Quiñónez-Falconi $F$, Bautista $E$, et al, for the INER Working Group of Influenza. Pneumonia and respiratory failure from swine-origin influenza A (H1N1) in Mexico. N Eng J Med. 2009;361 (Doi 10.1056/NEJMoa0904252).

2. Influenza A (H1N1)-update 14. Ginebra: OMS; 2009. (acceso 23 de junio de 2009).

3. Pandemic H1N1 2009, update 58 (acceso 7 de Julio de 2009). En: http:// www. who.int/csr/don/2009_07_06/en/index. html)

4. Situación de la Influenza A (H1N1). Ministerio de Salud de Argentina (acceso 7 de julio de 2009). En: www. msal.gov.ar/archivos/Parte_nueva_influenza_26_de_junio.pdf

5. Svoboda T, Henry B, Shulman L, et al. Public health measures to control the spread of the severe acute respiratory syndrome during the outbreak in Toronto. N Engl J Med. 2004;350:2352-61.

6. Pandemic (H1N1) 2009 Outbreak Epidemiological Update (accerso 7 de Julio de 2009). En: www. phac-aspc.gc.ca/alertalerte/ swine-porcine/ surveillance-eng. php)

7. Ministerio de Sanidad y política Social. Información sobre la gripe A/ H1N1 (acceso 7 de julio de 2009). En: www. msc. es/ servCiudadanos/ alertas/ informesGripeA/ 090706. htm

8. Fine MJ, Auble TE, Yealy DM, Hanusa BH, Weissfeld LA, Singer $D E$, et al. A prediction rule to identify low-risk patients with community-acquired pneumonia. N Engl J Med. 1997;336:24350.

9. Lim WS, Van der Eerden MM, Laing R, Boersma WG, Karalus N, Town GI, et al. Defining community acquired pneumonia severity on presentation to hospital: an international derivation and validation study. Thorax. 2003;58:377-82.

10. Blot SI, Rodríguez A, Solé-Violan J, et al. Effects of delayed oxygenation assessment on time to antibiotic delivery and mortality in patients with severe community-acquired pneumonia. Crit Care Med. 2007;35:2509-14. 